\title{
JOGO PEDAGÓGICO E A RESOLUÇÃO DE PROBLEMAS NO ENSINO DE ESTATÍSTICA E PROBABILIDADE NO ENSINO FUNDAMENTAL
}

\author{
Ailton Paulo de Oliveira Júnior ${ }^{\mathrm{a}}$, José António Fernandes ${ }^{\mathrm{b}}$, Joana dos Santos Silva ${ }^{\mathrm{a}}$, \\ Roberta Cristina de Faria Moreira $^{\mathrm{a}}$ e Valéria Ciabotti ${ }^{\mathrm{a}}$ \\ ${ }^{a}$ Universidade Federal do Triângulo Mineiro, Brasil \\ ${ }^{\mathrm{b}}$ Universidade do Minho, Brasil \\ drapoj@uol.com.br
}

O trabalho tem com objetivo apresentar e aplicar o jogo "Brincando com Estatística $e$ Probabilidade" para alunos do $9^{\circ}$ ano do Ensino Fundamental, com a intenção de facilitar a compreensão do conteúdo para o ensino e aprendizagem dos conceitos básicos da Estatística e da Probabilidade, utilizando a metodologia de resolução de problemas. Considerando os conteúdos propostos pelos Parâmetros Curriculares Nacionais no Brasil foram abordados: capacidade de leitura, interpretação e organização de dados; construção de tabelas e gráficos; concepção e compreensão de: espaço amostral, média, moda e mediana; o cálculo da probabilidade de um evento por uma razão; frequência absoluta e relativa. Após a aplicação do jogo, a maioria dos estudantes declarou apreciar a atividade e que aprenderam com ela, podendo-se perceber que serviu como suporte metodológico à Estatística e à Probabilidade.

\section{INTRODUÇÃO}

Frequentemente presencia-se a falta de preparação de professores em relação a conteúdos estatísticos, sendo que professores de Matemática, inclusive os recém-formados têm recebido poucos conhecimentos sobre Estatística na sua preparação profissional e que segundo Bratton (2000) acaba dificultando o ensino da Estatística pelos mesmos.

Os Parâmetros Curriculares Nacionais - PCN (1998) recomendam o trabalho com Estatística com a finalidade de que o estudante construa procedimentos para coletar, organizar, comunicar e interpretar dados, utilizando tabelas, gráficos e representações, e que seja capaz de descrever e interpretar sua realidade, usando conhecimentos matemáticos, como por exemplo, pesquisas sobre Saúde, Meio Ambiente, Trabalho e Consumo etc., de forma a contextualizar os conceitos estatísticos, transmitindo significado aos alunos.

Em relação à Probabilidade, os mesmos PCN consideram que esta auxilia na compreensão dos acontecimentos do dia-a-dia que são de natureza aleatória, permitindo a identificação de resultados possíveis desses acontecimentos. Destacam o acaso e a incerteza que se manifestam intuitivamente, portanto cabe à escola propor situações em que as crianças possam realizar experimentos e fazer observações dos eventos, como por exemplo, trabalhar com espaço amostral referente à quantidade de alunos da escola, quantidade de professores, etc.

Lopes (2008) aponta que o estudo do ensino da Estatística e da Probabilidade na Educação Básica torna-se indispensável ao cidadão nos dias de hoje e em tempos futuros, delegando ao ensino da matemática o compromisso de não só ensinar o domínio dos números, mas também a organização de dados, leitura de gráficos e análises estatísticas.

E ainda de acordo com Lopes (2008), o ensino e a aprendizagem de Estatística e de Probabilidade devem ser baseados em investigações e em resolução de problemas, de modo a permitir que o conhecimento matemático e estatístico possibilite ao estudante adquirir habilidades para compreender e lidar adequadamente com sua realidade.

Segundo os Parâmetros Curriculares Nacionais, Brasil (1998), os jogos constituem uma forma interessante de propor problemas, pois permitem que estes sejam apresentados de modo atrativo e favorecem a criatividade na elaboração de estratégias de resolução e busca de soluções. Além disso, propicia a simulação de situações-problema que exigem soluções vivas e imediatas, o que estimula o planejamento das ações; possibilitam a construção de uma atitude positiva perante os erros, uma vez que as situações sucedem-se rapidamente e podem ser corrigidas de forma natural, no decorrer da ação, sem deixar marcas negativas.

Segundo Polya (1978) resolver problemas é a realização específica da inteligência, e se a educação não contribui para o desenvolvimento da inteligência, ela está obviamente incompleta.

In: M.A. Sorto (Ed.), Advances in statistics education: developments, experiences and assessments. Proceedings of the Satellite conference of the International Association for Statistical Education (IASE), July 2015, Rio de Janeiro, Brazil. (C)2015 ISI/IASE iase-web.org/Conference_Proceedings.php 
Para Van de Walle (2009), um problema é qualquer tarefa ou atividade para a qual os estudantes não têm métodos ou regras prescritas ou memorizadas, nem a percepção de que haja um método específico para chegar à solução correta. Acrescentando um caráter subjetivo a esta questão, no contexto da metodologia aqui apresentada, consideramos que problema refere-se a tudo aquilo que não sabemos fazer, mas que estamos interessados em fazer.

Moura (1992) estabelece a relação entre jogo e problema, afirmando que podemos definir o jogo como um problema em movimento e problema porque envolve a atitude pessoal de querer jogar tal qual o resolvedor de problemas que só os tem quando estes lhe exigem busca de instrumentos novos de pensamento.

Para Grando (1995), o jogo representa uma situação-problema simulada e determinada por regras, em que o indivíduo busca, a todo o momento, elaborando estratégias e reestruturando-as, vencer o jogo, ou seja, resolver o problema. Este dinamismo característico do jogo é o que possibilita identificá-lo no contexto da resolução de problemas.

Pode-se perceber nos PCN um vínculo entre Estatística, Resolução de Problemas e a realidade dos alunos, como defende Dewey (1933) apud D‘Ambrósio e Ohio (2008, p. 1) ao propor que os projetos curriculares sejam baseados nas experiências dos alunos, e que tudo que fosse colocado para o aluno sem uma ligação com sua experiência se tornaria "inútil, como entulho, criando barreiras e obstruindo a possibilidade de pensar sobre os problemas enfrentados".

Segundo Grando (2000) a resolução de problemas e as atividades de jogos estão relacionadas quando, ao observarmos o comportamento de uma criança em situações de brincadeiras e/ou jogo, percebe-se o quanto ela desenvolve sua capacidade de fazer perguntas, buscar diferentes soluções, repensar situações avaliar atitudes, encontrar e reestruturar novas relações, ou seja, resolver problemas.

De acordo com os Parâmetros Curriculares Nacionais, Brasil (2000), a resolução de problemas não é uma atividade para ser desenvolvida em paralelo ou como aplicação da aprendizagem, mas uma orientação para a aprendizagem, pois proporciona o contexto em que se podem aprender conceitos, procedimentos e atitudes matemáticas.

O ensino-aprendizagem de matemática por meio da metodologia da resolução de problemas e da utilização de jogos possibilita aos estudantes a criação de estratégias para resolução das situações-problema, a apropriação de conceitos matemáticos e novas compreensões da matemática embutida na tarefa (Van de Walle, 2009).

De acordo com Grando (2004), a resolução de problemas está no processo de criação de estratégias e na análise, processada pelo aluno, das várias possibilidades de resolução. No jogo ocorre fato semelhante. Ele representa uma situação-problema determinada por regras, em que o indivíduo busca, a todo o momento, elaborando estratégias e reestruturando-as, vencer o jogo, ou seja, resolver o problema. Esse dinamismo característico do jogo é o que possibilita identificá-lo no contexto da resolução de problemas.

Desta forma, é trabalhado conceitos de Estatística e Probabilidade referentes ao $9^{\circ}$ ano do Ensino Fundamental, por meio da utilização de um jogo, com a intenção de facilitar o processo de ensino-aprendizagem tanto para o professor, quanto para o aluno, possibilitando além da assimilação do conteúdo, uma maior interação entre aluno/aluno e aluno/professor.

Desta forma, este trabalho tem como objetivo apresentar a contribuição dos jogos pedagógicos no processo ensino e aprendizagem da Estatística e da Probabilidade, utilizando a metodologia da Resolução de Problemas.

\section{METODOLOGIA}

Este trabalho foi desenvolvido com uma turma $9^{\circ}$ ano do Ensino Fundamental de uma escola estadual em Uberaba, Minas Gerais, Brasil, escola participante do projeto Programa Institucional de Bolsa de Iniciação à Docência - PIBID.

O programa tem como objetivo antecipar o vínculo entre os futuros professores e as salas de aula e com essa iniciativa, faz uma articulação entre a Educação Superior (por meio dos cursos de Formação de Professores), a escola de Educação Básica e os sistemas estaduais e municipais de Educação.

Dessa forma foi criado um jogo sobre Estatística e Probabilidade, considerando 
propostas dos Parâmetros Curriculares Nacionais - PCN, de forma a possibilitar aos alunos a leitura, interpretação e organização de dados; construção de tabelas e gráficos; concepção e compreensão de: espaço amostral, média, moda e mediana; indicação da probabilidade de um evento por meio de uma razão; frequência absoluta e relativa.

O jogo pedagógico foi confeccionado com a intenção de utilizá-lo para a fixação dos conteúdos de Estatística e Probabilidade no $9^{\circ}$ Ano do Ensino Fundamental, através da Resolução de Problemas.

Durante a realização do jogo, foi entregue uma folha de registro aos alunos, para que estes fizessem as anotações dos cálculos realizados durante a atividade, sendo em seguida recolhidas para avaliação dos cálculos realizados.

Este jogo é indicado para ser utilizado no $9^{\circ}$ ano do Ensino Fundamental e auxilia na fixação de conteúdos estatísticos e probabilísticos. Apresenta também situações-problemas, para que o aluno construa seu pensamento estatístico e probabilístico. Além disso, o jogo ainda ajuda o professor a identificar possíveis dificuldades dos alunos em relação a tais conteúdos. O jogo é composto por casas de Perguntas e de Saiba mais, há também casas de Avance e Retorne.

Sugere-se organização da classe em grupos com dois a quatro integrantes cada grupo e os recursos necessários são: um tabuleiro conforme modelo elaborado, peças coloridas (sendo 1 de cada cor) para a representação de cada um dos grupos um dado comum com seis faces e uma ampulheta para controlar o tempo de reposta ás questões.

O jogo tem as seguintes regras: (1) No início do jogo, os grupos devem colocar suas peças na casa "Partida" e em seguida, joga-se o dado para indicar qual grupo iniciará o jogo, ou seja, quem tirar o maior número do dado começa a partida. O grupo que obteve o maior número no lançamento do dado joga-o novamente e posiciona sua peça na casa correspondente ao valor do dado e assim sucessivamente os outros grupos; (2) Se a peça que representa o grupo cair na casa das perguntas, um dos componentes deste terá que retirar uma pergunta do monte de "Perguntas", ler para todos os outros membros do grupo, e em seguida todos os grupos participantes responderão à pergunta em folha de papel fornecida. Em o grupo respondendo acertadamente à questão, deverá andar no tabuleiro a quantidade de casas indicada na fícha da pergunta que se retirou, caso não acertem a questão, não andará nem recuará nenhuma casa, mas o grupo que não estiver participando da rodada terá o direito de respondê-la, podendo andar o total de casas correspondentes à questão caso acerte. Se os dois grupos errarem, o professor poderá interferir no jogo, indicando a resposta correta e comentando os erros cometidos pelos grupos; (3) Se a peça representante do grupo cair na casa "Saiba +", deverá ler a curiosidade em voz alta para todos os componentes do grupo e depois deverá andar no tabuleiro a quantidade de casas correspondentes na ficha; (4) Se a peça representante do grupo cair na casa "Avance casas", deverá avançar o tanto de casas correspondentes. Caso a peça caia na casa "Retornar casas", deverá retornar o tanto de casas correspondentes; (5) Ganha a partida o grupo que completar uma volta completa no tabuleiro.

Após a aplicação do jogo, duas semanas depois, foi aplicado um teste de avaliação que serviu como uma das notas que comporiam a nota do bimestre letivo. O teste é composto por cinco questões sendo 2 (duas) questões com conteúdos estatísticos, ou seja, frequência relativa e simples, construção de tabela de frequências, média, moda, mediana; e três questões com conteúdos de Probabilidade, ou seja, probabilidade de eventos.

Durante o jogo que contém questões com foco na Resolução de Problemas e também na resolução dos problemas no teste de avaliação, observou-se que os alunos seguiram as etapas que segundo Polya (1978), fazem parte da lógica na solução de problemas, quais sejam: (1) compreensão do problema; (2) estabelecimento de um plano; (3) execução do plano; (4) retrospecto ou verificação.

Cabe também destacar que os problemas do jogo e do teste de avaliação foram elaborados seguindo a compreensão da Resolução de Problemas caracterizada por Dante (2000), onde os problemas matemáticos podem ser classificados em seis categorias: problemas de reconhecimento, problemas de algoritmos, problemas-padrão, problemas-processo, problemas de aplicação e quebra-cabeça.

Após todo este processo foi aplicado um questionários de perguntas abertas pra também identificar de que forma os alunos consideraram o jogo como uma metodologia de ensino que 
veio auxiliar na compreensão dos conteúdos estatísticos e probabilísticos. As questões foram as seguintes: (1) Escreva se gostou ou não gostou do jogo. (2) De que forma o jogo o ajudou, ou não, a fixar os conteúdos estatísticos e probabilísticos que você já havia estudado. (3) Você considera que o jogo o ajudou a ter um bom aproveitamento no teste que a professora a aplicou e de que forma?

\section{O JOGO PEDAGÓGICO E A RESOLUÇÃO DE PROBLEMAS}

A aplicação do jogo foi realizada em uma turma de $9^{\circ}$ ano de uma escola estadual em Uberaba, Minas Gerais, Brasil, e utilizadas duas aulas para a sua prática. Primeiramente foi informado aos alunos sobre a atividade, e em seguida o jogo foi apresentado aos alunos e explicadas as suas regras.

Como se tratava de um teste para a verificação das questões elaboradas e as regras do jogo foram disponibilizados dois tabuleiros para uma turma de 24 alunos. Para que pudesse ser começado o jogo, pediu-se aos alunos que se dividissem em seis grupos, cada grupo com 2 integrantes (dois contra dois).

Assim um tabuleiro foi entregue a cada grupo, e em seguida, os alunos foram orientados que a cada pergunta respondida eles teriam cinco minutos para responder controlado pela ampulheta. Cada grupo foi acompanhado para apoio a possíveis dúvidas no desenvolvimento do jogo.

Ao final do jogo recolheram-se as folhas que os alunos utilizaram para resolver as questões e pediu-se para que esses escrevessem o que acharam da atividade realizada. A maioria dos alunos disse ter gostado da atividade e que aprenderam de uma forma divertida. Encontramse abaixo um trecho do que foi escrito pelos alunos:

"Eu gostei muito do jogo, achei que ajudou muito. Reforçou bastante o que a professor ensinou. Acho que se cada matéria dada tivesse um jogo tipo este, nos ajudaria muito."

Durante a aplicação do jogo ao Grupo 1, observamos que os alunos demonstraram entusiasmo. Estes expuseram que as aulas de Matemática ficariam melhores se houvesse um jogo como o apresentado e que era bom pra fixar o conteúdo.

Descrevemos uma das etapas (ou questão) do jogo em que os alunos tiveram dificuldades, ou seja:

"Os seguintes dados representam diferentes preços (em $R \$$ ) de um determinado produto pesquisado em 20 lojas: 50, 50, 51, 51, 51, 51, 51, 52, 52, 52, 52, 52, 52, $53,53,53,53,53,53,54$. Considerando os dados acima, determine o percentual de ocorrência dos diferentes preços e comente os resultados?".

Questões similares a esta também geraram dificuldades durante o jogo, por terem muitos valores e neste caso, acreditamos dever-se a dificuldade de memorização ou visualização de tantos valores pelos alunos. Neste caso, foi necessário que se escrevesse os números no quadro branco para que todos os jogadores tivessem acesso aos valores da questão. Percebeu-se que esse tipo de questão fez perder a dinâmica do jogo, tornando a rodada monótona.

Observou-se também que os alunos apresentaram deficiências ou erravam a questão por falta de atenção na realização de operações básicas de matemática como: adição; porcentagem; regra de três; e divisão.

Grande parte dos alunos mostrou domínio em relação em relação aos conteúdos estatísticos e probabilísticos, mas percebeu-se que em algumas ocasiões consultavam o caderno de anotações de aulas e o livro didático. Algumas vezes interviu-se no processo auxiliando os alunos a desenvolverem certas operações matemáticas e lembrá-los do conteúdo anteriormente ministrado.

Trazemos a seguir alguns aspectos da aplicação do jogo no Grupo 2, referentes a resolução de algumas questões sorteadas.

Observou-se que a maioria dos alunos acertavam as questões, tanto no grupo que havia retirado a pergunta, bem como o grupo adversário.

Percebeu-se que os alunos dominavam o conteúdo, principalmente àqueles relacionados 
à Probabilidade. Indicamos aqui uma das questões sorteadas durante o jogo que perguntava:

"Qual a probabilidade de sair o número sete no lançamento de um dado?".

A partir dessa pergunta os alunos se entreolharam meio confusos, e então um dos alunos comentou:

"Isso é pegadinha, não é possivel sair um sete no dado".

Após esta questão, foi explicado que quando se trata de um acontecimento impossível, a probabilidade de ocorrência é igual a 0 (zero).

Aqui também destacamos uma das questões que contemplava a leitura de um gráfico e indicar o valor da "Moda", valor mais frequente das informações fornecidas, como, por exemplo, a da Figura 1.

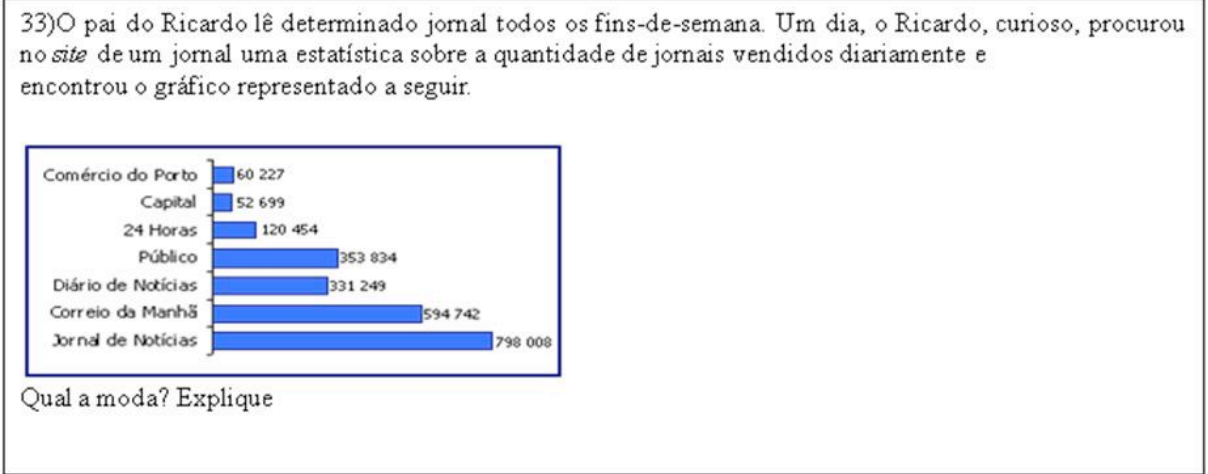

Figura 1. Questão 33 do jogo

Observou-se que os alunos não conseguiam resolver, pois tentavam efetuar operações, sendo que esta questão envolvia a simples leitura do gráfico para a obtenção da resposta solicitada.

Apresentamos a seguir as discussões surgidas a partir das dúvidas dos alunos. Desta forma, quando se percebeu que os alunos tentavam fazer operações e que estavam se distanciando do objetivo da questão, questionamos os alunos da seguinte forma:

"Vocês tem certeza que neste problema é necessário realizar operações matemáticas?"

"Deem uma olhada no que pede o problema."

Nesse momento os alunos leram novamente a questão, e então perguntamos:

"O que é moda?".

Então os alunos responderam:

"É o que acontece mais".

Aí questionamos:

"Se a moda é o evento que ocorre com maior frequência e é o que acontece mais, qual é a moda nessa questão?"

Aí os alunos começaram a perceber que não precisavam fazer nenhum tipo de operação matemática, e sim apenas analisar o gráfico com atenção. Então começaram a responder:

"Então a moda é o Jornal de Notícias". responderam:

Questionaram-se então os alunos do porquê de o Jornal de Notícias ser a moda, e

"Porque é o que vende mais".

Depois de confirmar que a resposta estava correta formalizou-se o conceito de moda.

Pôde-se verificar com a aplicação do jogo, que a maioria dos alunos gostou da atividade, pois permitiu que os alunos saíssem da rotina. A maioria dos alunos participou ativamente do jogo, mas verificou-se que poucos alunos não tentavam responder as questões, ficavam querendo sair da sala, e pegavam as respostas prontas com os colegas. Isso pode ter ocorrido devido á falta de interesse do aluno em jogar, ou devido ao fato de ter apenas um tabuleiro para 16 alunos, fazendo com que os alunos que estavam mais distantes do tabuleiro se desmotivassem. 
Assim percebeu-se que o jogo deve ser jogado por no máximo 8 integrantes (quatro contra quatro) para possibilitar que todos participem das resoluções das questões e que estas não deve conter muitos valores pois também causa desinteresse e também torna o jogo monótono.

E em seus relatórios a maioria dos alunos disse ter gostado da atividade e que haviam aprendido bastante com a mesma. Um dos depoimentos mostra esta opinião:

"O jogo elaborado foi bem criativo, nele podemos aprender de um modo mais divertido".

\section{CONSIDERAÇÕES FINAIS}

Com a aplicação do jogo, percebemos que o mesmo funcionou como apoio metodológico para a aula de Estatística e Probabilidade, deixando-a mais estimulante e atrativo para os alunos.

Além disso, contribuiu para que estes reforçassem o conhecimento já ministrado anteriormente sobre os conteúdos aqui abordados. Observou-se que os alunos tiveram um bom aproveitamento no teste na medida em que consideraram o jogo como elemento motivacional e que contribuiu para a fixação dos conteúdos.

Concordamos com Grando (2004) quando expõe que o trabalho com jogos possibilita que o aluno participe da construção de seu conhecimento, deixando de ser passivo e se tornando agente de sua aprendizagem. Na situação de jogo o aluno se torna mais confiante, expressa o que pensa e tira suas próprias conclusões. Dentre outras coisas, o jogo favorece o desenvolvimento da criatividade, do senso crítico, da participação, da competição "sadia", da observação, das várias formas de uso da linguagem e do resgate do prazer em aprender.

Durante a aplicação do jogo é fundamental que se realize intervenções pedagógicas para que os alunos possam perceber e participar da construção dos conceitos estatísticos e probabilísticos. Cabe também fazer uma boa elaboração da atividade, escolhendo jogos e questões que proporcionem desafios aos alunos, e tendo claros seus objetivos e o conteúdo a ser trabalhado. Assim, acreditamos que se deve planejar bem suas atividades para que estas não tenha um caráter de "jogar por jogar" e sim que possa auxiliar os alunos no processo de ensino e aprendizagem da Estatística e da Probabilidade.

\section{REFERÊNCIAS}

Brasil. (1998). Secretaria de Educação Fundamental. Parâmetros curriculares nacionais: Matemática/Secretaria de Educação Fundamental. MEC / SEF, Brasília.

Brasil. (2000). Ministério da Educação. Secretaria de Educação Fundamental. Parâmetros Curriculares Nacionais. V.3. Rio de Janeiro: DP\&A.

Bratton, G. (2004). The Role of Technology in Introductory Statistics Classes. Statistical Education Research Newsletter, 1(1).

D’Ambrósio, B. S. \& Ohio, M. U. (2008). A Evolução da Resolução de Problemas no Currículo Matemático. In Seminário de Resolução de Problemas, 1., 2008, Rio Claro. Anais eletrônicos... Rio Claro: GTERP.

Dante, R. D. (2007). Didática da Resolução de Problemas de Matemática. São Paulo, Ática.

Grando, R. C. (1995). O Jogo e suas Possibilidades Metodológicas no Processo EnsinoAprendizagem da Matemática. Dissertação de Mestrado em Educação - UNICAMP, Campinas.

Grando, R.C. (2000). O conhecimento matemático e o uso de jogos na sala de aula. Campinas, SP. Tese de Doutorado. Faculdade de Educação, UNICAMP.

Grando, R.C. (2004). O jogo e a matemática no contexto da sala de aula. São Paulo: Paulus.

Lopes, C.A.E. (2008). O ensino da estatística e da probabilidade na educação básica e a formação dos professores. Caderno Cedes, Campinas, 28(74), 57-73.

Moura, M. O. (1992). O Jogo e a construção do conhecimento matemático. São Paulo: FDE.

Polya, G. (1978). A arte de resolver problemas. Rio de Janeiro: Interciência.

Van de Walle, J. A. (2009). Matemática no ensino fundamental: formação de professores e aplicação em sala de aula. Porto Alegre: Artmed, 2009. 